\title{
Prevalence of non-motor disorders in Parkinson`s disease
}

\author{
Natalia Yu. Safonova ${ }^{*}$, Margarita R. Sapronova ${ }^{2}$, Oksana A. Gavrilyuk ${ }^{2}$, Tatiana E. Popova ${ }^{3}$, \\ Alexey A. Tappakhov ${ }^{4}$
}

Citation: Safonova, N.Yu.;
Sapronova, M.R.; Gavrilyuk, O.A.;
Popova, T.E.; Tappakhov, A.A.
Prevalence of non-motor disorders
in Parkinson`s disease. Personalized
Psychiatry and Neurology 2021, 1
(2): 117-125.
https://doi.org/10.52667/2712-9179https://doi.org/10

\section{Chief Editor:}

Nikolay G. Neznanov, D Med Sci, Professor

Received: 08 August 2021 Accepted: 22 October 2021 Published: 15 November 2021

Publisher's Note: V. M. Bekhterev NMRC PN stays neutral with regard to jurisdictional claims in published maps and institutional affiliations

Copyright: (C) 2021 by the authors.
1 V.M. Bekhterev National Medical Research Centre for Psychiatry and Neurology; 192019 Saint-Petersburg, Russia; astarta10@andex.ru (N.Yu.S.)

2 V.F. Voino-Yasenetsky Krasnoyarsk State Medical University; 660022 Krasnoyarsk, Russia; sapronova.mr@yandex.ru (M.R.S.), Oksana.gavrilyuk@mail.ru (O.A.G.)

3 Yakutsk Scientific Centre for Complex Medical Problems; 677000, Yakutsk, Russia; tata2504@yandex.ru (T.E.P.)

4 M.K. Ammosov North-Eastern Federal University; 677000, Yakutsk, Russia; dralex89@mail.ru (A.A.T.)

* Correspondence: astarta10@andex.ru , Tel.: +7 (812) 6700029 (N.Yu.S).

\begin{abstract}
Background: to reveal the prevalence of non-motor disorders in Parkinson's disease (PD), we analyzed both Russian and international studies on the issue of PD-associated non-motor disorders in Caucasian patients; (2) Methods: We have carried out a search for full-text Englishand Russian-language articles published during the last ten years (from 2010 to 2020) in PubMed, Scopus, Web of Science, Springer, Clinical case, and E-library databases using multiple versions of keywords and their combinations. (3) Results: General prevalence of PD-associated non-motor disorders proved to be high. At the same time, we did not find significant differences between the prevalence of cognitive, affective, or behavioral disorders in PD patients. However, depression was found to be more common in PD patients in the Russian Federation; (4) Conclusions: According to the results of our review, cognitive and affective disorders in PD represent the issues of major concern.
\end{abstract}

Keywords: non-motor disorders; non-motor symptoms; Parkinson's disease; cognitive disorders; affective disorders; behavioral disorders.

\section{Introduction}

Parkinson's disease (PD) is a common neurodegenerative disease that predominantly affects dopaminergic neurons in the substantia nigra pars compacta. The prevalence of PD in the world is $0.3 \%$, and the quantity of PD cases is gradually increasing with aging of the world population $[1,2,3]$. PD remains the second most common neurodegenerative disease after Alzheimer's disease [4]. The world's population over 60 years old has about $1 \%$ risk for PD development [5].

Among PD symptoms there are not only motor symptoms (tremor, hypokinesia, postural instability, and rigidity), but also non-motor manifestations (affective, cognitive, behavioral, autonomic and other disorders). These symptoms significantly worsen the quality of life of PD patients and their relatives. At the same time, they increase the economic burden due to the need for additional treatment of non-motor manifestations and the need for additional nursing care. $[6,7,8]$. Unfortunately, non-motor symptoms cannot be corrected with standard dopaminergic therapy prescribed for PD patients [9]. Non-motor symptoms often appear in the preclinical stage, while motor symptoms are commonly characterized by a pronounced degree of neurodegeneration, indicating the death of about $80 \%$ of dopaminergic neurons [10].

The aim of our investigation was to review both Russian and international studies on the issue of PD-associated non-motor disorders in Caucasian patients. 


\section{Materials and Methods}

We have carried out a search for full-text English- and Russian-language articles published during the last ten years (from 2010 to 2020) in PubMed, Scopus, Web of Science, Springer, Clinical case, and E-library databases using multiple versions of keywords and their combinations. Only the articles containing the information about the sample size of the studied patient groups were included in our review.

\section{Results}

\subsection{Cognitive disorder prevalence in PD patients}

In total, 3493 English-language articles and 55 Russian-language publications were analyzed. For further study, 475 works were selected from the English-language papers. However, only 50 studies most closely matched the objectives of our review, these full-text articles were included in our review. Yearly quantity of studies on non-motor disorders in PD patients is shown in Figures 1 and 2.

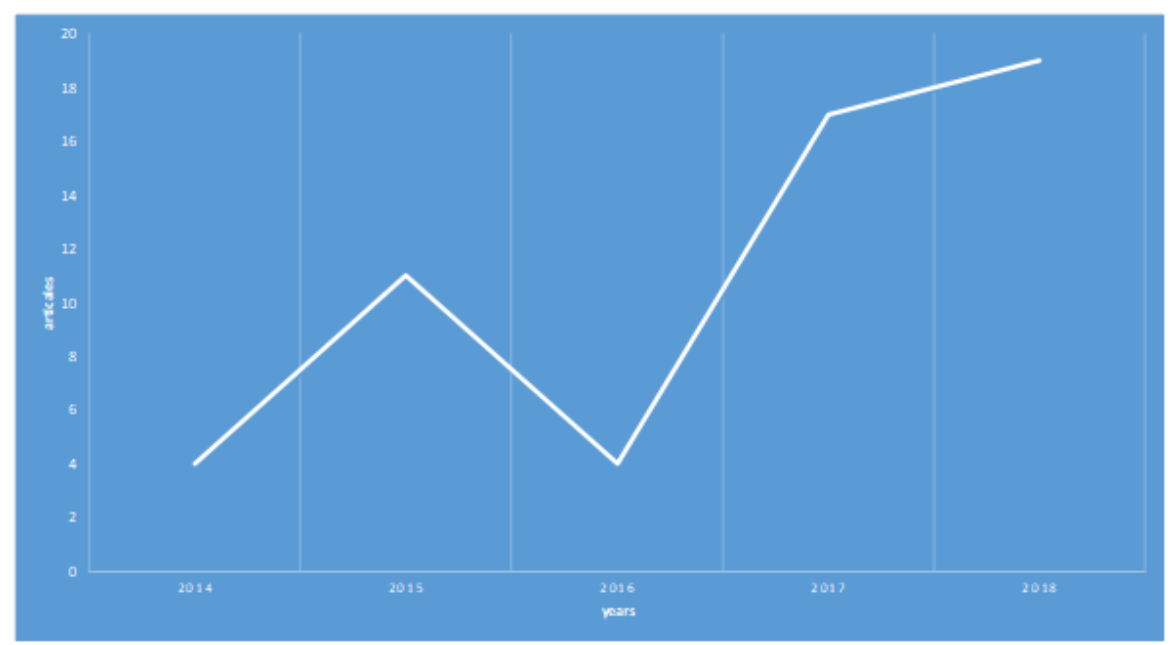

Figure 1. The dynamics of the number of published articles addressing the results of the epidemiological PD studies in the Russian Federation.

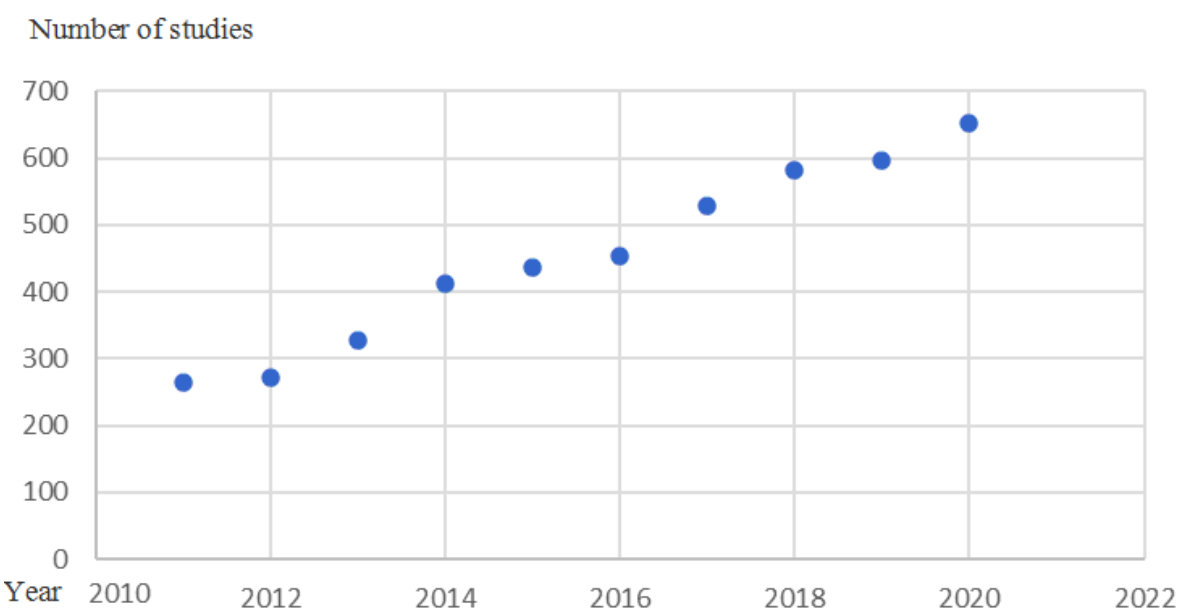

Figure 2. The dynamics of the number of internationally published articles (in English) addressing the results of the epidemiological PD studies. 
We revealed a growing interest of Russian researchers to the problem of PDassociated non-motor disorders (Fig. 1). The number of international studies on the problem under consideration for the analyzed period of time was consistently high (2010-2020), this demonstrating extreme relevance of the issue. The analysis of the studies devoted to PD-associated non-motor disorders carried out in the Russian Federation, USA, Italy, Netherlands, and Switzerland is provided below (Tables 1-4). The present study covered the works on cognitive, affective, psychotic, and behavioral disorders in PD patients.

Table 1. Cognitive disorder in Parkinson's disease.

\begin{tabular}{lccc}
\hline Year & Country & Prevalence & Reference number \\
\hline 2016 & Russia & $57.6 \%$ & 11 \\
2016 & Russia & $53.9 \%$ & 12 \\
2016 & Russia & $19.4 \%$ & 13 \\
2016 & Russia & $22 \%$ & 14 \\
2015 & Russia & $67 \%$ & 15 \\
2015 & Russia & $22.4 \%$ & 16 \\
2015 & Russia & $36 \%$ & 17 \\
2014 & Russia & $62.5 \%$ & 18 \\
2014 & Russia & $35.7 \%$ & 19 \\
2016 & Belarus & $44 \%$ & 20 \\
2019 & USA & $14.7 \%$ & 21 \\
2019 & USA & $15.8 \%$ & 22 \\
2018 & USA & $10.9 \%$ & 23 \\
2017 & USA & $67.4 \%$ & 24 \\
2015 & USA & $9 \%$ & 25 \\
2017 & Canada & $44.5 \%$ & 26 \\
2017 & Canada & $47 \%$ & 27 \\
2016 & Canada & $64 \%$ & 28 \\
2015 & Italy & $28.6 \%$ & 29 \\
2015 & Italy & $49 \%$ & 31 \\
2017 & Spain & $37.2 \%$ & 32 \\
2016 & Spain & $60.5 \%$ & 30 \\
2014 & Denmark & $34 \%$ & 31 \\
2015 & Great Britain & $30 \%$ & 32 \\
2015 & Great Britain & $29.4 \%$ & 32 \\
2015 & Norway & $39.4 \%$ & 32 \\
2015 & Netherlands & $35 \%$ & 32 \\
\hline & & &
\end{tabular}

The analysis of epidemiological studies of PD-associated cognitive disorders demonstrated the samples heterogeneity, with a large scatter in the number of patients included in the studies (from 28 to 1406 people), this complicating the statistical analysis of the data obtained (Table 1). In the Russian studies, sample size was small and varied from 28 to 140 patients. The prevalence of cognitive disorders in PD patients ranged from $19.4 \%$ to $67 \%$. The average prevalence of cognitive disorders in the Russian patients was $41.8 \pm 23 \%$.

In the analyzed publications assessing the prevalence of PD-associated cognitive disorders in the USA, the sample size varied from 431 to 1406 patients. The frequency of occurrence of PD-associated cognitive disorders varied from $9 \%$ to $67.4 \%$. The average prevalence was $23.5 \pm 10.6 \%$. 
The average prevalence of cognitive disorders in PD was $55.5 \pm 8.5 \%$ in Canada (we analyzed two publications describing the data of 51 and 70 patients).

In European countries, the prevalence of cognitive disorders ranged from 34 to $50.6 \%$, while the sample size varied from 43 to 108 people. The average prevalence of cognitive impairment in PD was $45 \pm 13.3 \%$ in Europe. The weighted average of the prevalence of cognitive disorders associated with PD was $41.5 \pm 18.5 \%$ in the world. Our analytical data were consistent with the literature review by Cosgrove J. et al. (2015), which presented data from the studies on the cognitive impairment in PD prevalence conducted in different countries, according to which cognitive impairments are detected in $26.7-42.5 \%$ in PD patients [32].

The prevalence of PD-associated cognitive impairments in the world is shown in Figure 3.

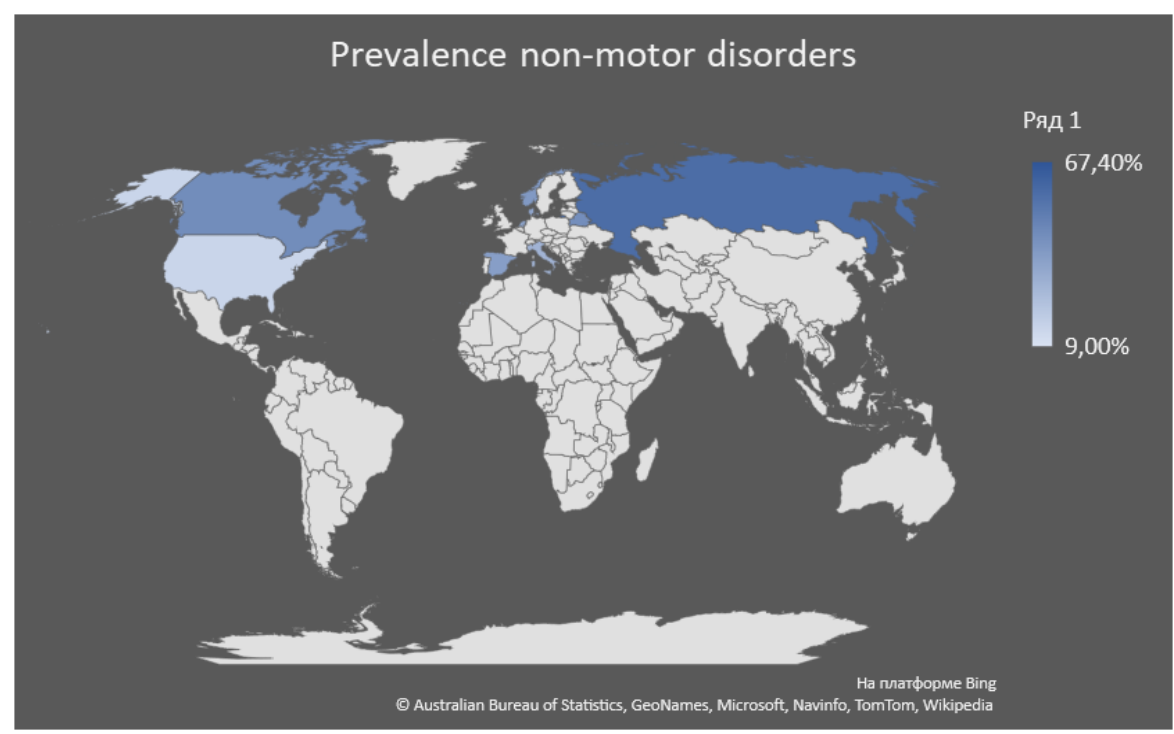

Figure 3. Geographic distribution of PD-associated cognitive disorders.

\subsection{Behavioral disorder prevalence in PD patients}

In the analyzed publications, from $40 \%$ to $50.6 \%$ of PD cases (the sample being from 21 to 340 patients) were reported to be characterized with behavioral disorders (see Table 2). The world average prevalence of behavioral disorders in PD was estimated as $38.1 \pm$ $11 \%$. Behavioral disorders are presented mainly in review articles; and we found significantly less publications on the occurrence of these PD-associated manifestations for the period 2010-2020.

Table 2. Prevalence of behavioral disorders in Parkinson's disease.

\begin{tabular}{ccccc}
\hline Year & Country & Prevalence & Sample size Reference number \\
\hline 2019 & Switzerland & $40 \%$ & 64 & 33 \\
2017 & Russia & $23.8 \%$ & 21 & 34 \\
2017 & Russia & $50.6 \%$ & 340 & 35 \\
2017 & USA & $13.6 \%$ & 3090 & 49 \\
2014 & Spain & $39 \%$ & 233 & 50 \\
\hline
\end{tabular}




\subsection{Affective disorder prevalence in $P D$ patients}

We analyzed publications on affective disorders in PD patients. The works addressing the issues of PD-associated depression and anxiety were analyzed separately.

According to this analysis, in Europe (with 414 patients sample size) and the USA (with 120 patients sample size), $21.2-32.8 \%$ of PD patients have depression (see Table 3). The indicators are significantly higher and range from 26.1 to $95.7 \%$ in the Russian Federation. The sample size varied from 28 to 322 cases. The average prevalence of depression in PD patients was $64.5 \pm 19.9 \%$ in the Russian Federation. The world weighted average indicator of PD-associated depressive disorders was $62.6 \pm 20.8$. 
Table 3. Prevalence of affective disorders in Parkinson's disease.

\begin{tabular}{|c|c|c|c|c|}
\hline Year & Country & Prevalence & Sample size & Reference number \\
\hline \multicolumn{5}{|c|}{ Depression in Parkinson`s disease } \\
\hline 2017 & Russia & $67.5 \%$ & 206 & 34 \\
\hline 2016 & Russia & $84 \%$ & 132 & 11 \\
\hline 2016 & Russia & $50 \%$ & 24 & 36 \\
\hline 2016 & Russia & $41.9 \%$ & 31 & 13 \\
\hline 2016 & Russia & $39.7 \%$ & 74 & 37 \\
\hline 2016 & Russia & $95.7 \%$ & 54 & 12 \\
\hline 2015 & Russia & $26.1 \%$ & 33 & 39 \\
\hline 2015 & Russia & $75 \%$ & 28 & 17 \\
\hline 2015 & Russia & $90 \%$ & 322 & 40 \\
\hline 2015 & Russia & $67 \%$ & 33 & 15 \\
\hline 2015 & Russia & $56.5 \%$ & 35 & 41 \\
\hline 2014 & Russia & $75 \%$ & 140 & 19 \\
\hline 2014 & Netherlands & $21.2 \%$ & 414 & 42 \\
\hline 2018 & USA & $32.8 \%$ & 120 & 44 \\
\hline \multicolumn{5}{|c|}{ Anxiety in Parkinson`s disease } \\
\hline 2018 & Russia & $67 \%$ & 114 & 44 \\
\hline 2016 & Russia & $67 \%$ & 132 & 11 \\
\hline 2015 & Russia & $80 \%$ & 322 & 40 \\
\hline 2015 & Russia & $44 \%$ & 33 & 14 \\
\hline 2015 & Russia & $\begin{array}{c}63.2 \% \text {-severe } \\
36.8 \% \text { - moder- } \\
\text { ate }\end{array}$ & 35 & 41 \\
\hline
\end{tabular}

According to the studied publications from the Russian Federation, anxiety disorders comorbid with PD are also quite common. Specifically, with the sample sizes varying from 33 to 322 patients, the comorbidity of anxiety in PD ranged from 44 to $80 \%$ (Table 3). The weighted average of the prevalence of PD-associated anxiety was $64 \pm$ $12.01 \%$ in the Russian Federation.

Also, psychotic disorders proved to be among common non-motor disorders in PD (Table 4).

Table 4. Prevalence of psychotic disorders in Parkinson's disease.

\begin{tabular}{lcccc}
\hline Year & Country & Prevalence & Sample size & Reference number \\
\hline 2016 & Russia & $6.5 \%$ & 31 & 13 \\
2014 & Russia & $6.6 \%$ & 136 & 18 \\
2019 & USA & $37.6 \%$ & 1406 & 45 \\
2018 & USA & $32.8 \%$ & 120 & 43 \\
2018 & USA & $22.6 \%$ & 137 & 44 \\
2017 & USA & $32.7 \%$ & 101 & 47 \\
2016 & Brazil & $15.7 \%$ & 102 & 48 \\
2014 & Netherlands & $21.2 \%$ & 414 & 42 \\
\hline
\end{tabular}


The data obtained in the Russian Federation were more homogeneous and varied from 6.5 to $6.6 \%$, with sample sizes of 31 and 136 patients, respectively. In the Russian Federation, the average prevalence of psychotic disorders was $6.55 \%$. In the USA, the frequency of psychotic disorders ranged from 3 to $37.6 \%$, with sample sizes from 101 to 1406 patients), while the average prevalence of psychotic disorders was $25.7 \pm 12.38 \%$. The world weighted average of the prevalence of PD-associated psychotic disorders was $19.7 \pm 12.8 \%$.

\section{Discussion}

When considering the results of the studies covering the problem of non-motor disorders in PD patients, we analyzed such non-motor impairments as cognitive, behavioral, affective, and psychotic ones. We have shown that the prevalence of non-motor disorders in PD is high, and the problem under consideration is extremely relevant.

At the same time, we did not find significant differences in the prevalence of cognitive, affective, or behavioral disorders in PD patients. However, according to the analyzed publications, the most common disorder in PD patients in the Russian Federation is depression. Higher rates of depression in the Russian Federation are likely to be associated with local socioeconomic circumstances, leading to lower rates of life quality and high social stigmatization in the Russian Federation.

Mental state of PD patients is known to be mostly characterized by cognitive and affective impairments. This causes a high scientific interest towards these PD-associated disorders. Consequently, a large number of scientific publications on this topic appear (Fig. 4) including those which address the problem of the revision of PD treatment strategy and the use of disease-modifying therapy with the inclusion of medicines affecting dopaminergic neurons as well as anti-dementia, nootropic, and antipsychotic drugs.

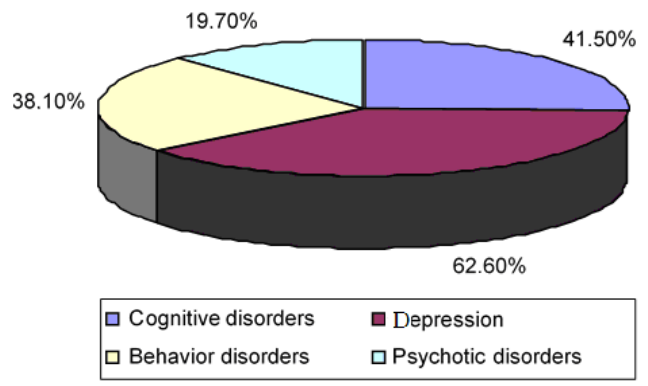

Figure 3. Global prevalence of PD-associated non-motor disorders.

\section{Conclusions}

A high prevalence of non-motor disorders among patients with PD dictates the need for taking these cognitive and affective impairments into account when developing an individual program for the treatment and rehabilitation of PD patients.

Author Contributions: Conceptualization, N.Y.S., M.R.S., T.E.P.; methodology, N.Y.S.; software, N.Y.S.; validation, N.Y.S., M.R.S.; formal analysis, N.Y.S.; investigation, N.Y.S., M.R.S., O.A.G., T.E.P. writing-original draft preparation, N.Y.S., M.R.S.; writing-review and editing, N.Y.S., T.E.P., O.A.G.; visualization, N.Y.S; supervision, T.E.P. All authors have read and agreed to the published version of the manuscript.

Funding: This research received no external funding

Conflicts of Interest: The authors declare no conflict of interests 


\section{References}

1. Krivonos, O.V. Organization of medical care for patients with Parkinson's disease in modern socio-economic conditions. Parkinson's disease and movement disorders. A Physician's Guide to the 3rd National Congress on Parkinson's Disease and Movement Disorders (with international participation), 2014, S. 217-220 (in Russ.).

2. Tappakhov, A.A.; Popova, T.E.; Nikolayeva, T.Ya.; Shnayder, N.A.; Petrova, M.M. Epidemiology of Parkinson's disease in the world and in Russia. Transbaikal Medical Bulletin 2016, 4, 151-159 (in Russ.).

3. Razdorskaya, V.V.; Voskresenskaya, O.N.; Yudina, G.K. Parkinson's disease in Russia: prevalence and incidence. Saratov Journal of Medical Scientific Research 2016, 3, 379-384 (in Russ.).

4. Ascherio, A.; Schwarzschild, M.A. The epidemiology of Parkinson's disease: risk factors and prevention. The Lancet Neurology. 2016, 15, 12, 1257-1272. doi:10.1016/S1474-4422(16)30230-7.

5. Tysnes, O.B.; Storstein, A. Epidemiology of Parkinson's disease. J Neural Transmission. 2017, 124, 8, 901-905. doi:10.1007/s00702-017-1686-y.

6. Hurt, C.S.; Rixon, L.; Chaudhuri, K.R.; Moss-Morris, R.; Samuel, M.; Brown, R.G. Barriers to reporting non-motor symptoms to health-care providers in people with Parkinson's. Parkinsonism Relat Disord. 2019, 1353-8020(19), 30209-3. doi: 10.1016/j.parkreldis.2019.04.014.

7. Gusev, E.I.; Gext, A.B.; Pavlov, H.A.; Popov G.R. Pharmacoeconomics of Parkinson's disease. Materials of the 1st National Congress on Parkinson's Disease and Movement Disorders 2010, 173 - 178 (in Russ.).

8. Milchakova, A.E.; Popov, G.R.; Bykov, A.V.; Gekht, A.B. Clinical and pharmacoeconomic analysis of the use of the drug piribedil (Pronoran) in the treatment of Parkinson's disease. Journal of Neurology and Psychiatry 2008, 4, 49-55 (in Russ.).

9. Kalia, L. V.; Lang, A. E. Parkinson's disease. The Lancet. 2015; 386, 9996, 896-912. doi:10.1016/s0140-6736(14)61393-3.

10. Hustad, E.;Aasly, J.O. Clinical and Imaging Markers of Prodromal Parkinson's Disease. Front Neurol. $2020,11,395$. doi:10.3389/fneur.2020.00395

11. Nodel, M.R.; Danilova, N.N.; Glozman, Zh.M.; Yakhno, N.N. The relationship between cognitive and emotional-affective disorders in patients with Parkinson's disease. Neurological journal 2016, 21, 6, 338-343 (in Russ.).

12. Poverennova, I.E.; Kalinin, V.A.; Mukhina, S.A. Identification of non-motor disorders in Parkinson's disease and determination of their relationship with motor disorders. Saratov Journal of Medical Scientific Research 2016, 12, 2, $281-285$ (in Russ.).

13. Tappakhov, A.A.; Nikolaeva, T.Ya.; Okoneshnikova, L.T.; Petrova, A.Yu. Non-motor manifestations of Parkinson's disease in patients living in the Republic of Sakha (Yakutia). Ecology and human health in the North, a collection of scientific works of the 4th Congress with international participation 2016, 561-566.

14. Lytayev, S.A.; Susin D.S. PET diagnosis of cognitive impairment in patients with Parkinson's disease. Pediatrician 2016, 7, 1, 63-68 (in Russ.).

15. Rabadanova, E.A,; Gelpey, M.A.; Goncharova, Z.A. Non-motor symptoms of Parkinson's disease. their structure and impact on the quality of life of patients. Practical medicine 2015, 90, 5, 111-115 (in Russ.).

16. Khanova, M.N. Non-motor manifestations of Parkinson's disease. Eurasian Union of Scientists 2015, 19, 10-1, 124-126 (in Russ.).

17. Yakovleva, T.V.; Karakulova,Yu.V.; Demchuk, N.D. Comprehensive comparative psychometric testing of patients with Parkinson's disease. Modern problems of science and education 2015, 6, 85 (in Russ.).

18. Smolentseva, I.G.; Chupina, L.P.; Amosova, N.A.; Krivonos, O.V. Clinical assessment of the progression of Parkinson's disease. S.S. Korsakov Journal of Neurology and Psychiatry 2014, 14, 6-2, 36-40 (in Russ.).

19. Antonen, E.G.; Khyanikyaynen, I.V.; Kirsan, S.A.; Ancheyeva, E.G. Clinical characteristics of Parkinson's disease in the Republic of Karelia. Scientific notes of Petrozavodsk State University 2014, 145, 8-2: 41-47 (in Russ.).

20. Mazurenko, E.V. Neuroimaging criteria for diagnosis and clinical features of cognitive impairment in patients with Parkinson's disease. Medical news 2016, 4, 73-76 (in Russ.).

21. Lemprière, S. Frontotemporal dementia risk variant accelerates cognitive decline in Parkinson disease. Nature Reviews Neurology 2019, doi:10.1038/s41582-019-0196-y.

22. Shprecher, D.; Zhang, N.; Halverson, M.; Savica R. Parkinsonism Risk Factors in Salt Lake City, Utah: A Community-Based Study. Brain Sci. 2019, 9, 3, 71. doi:10.3390/brainsci9030071.

23. Chahine, L.M.; Urbe, L.; Caspell-Garcia C.; Aarsland, D.; Alcalay, R.; Barone, P.; Burn, D.; Espay, A.J.; Hamilton, J.L.; Hawkins, K.A.; Lasch, S.; Leverenz, J.B.; Litvan, I.; Richard, I.; Siderowf, A.; Coffey, C.S.; Simuni, T.; Weintraub, D. Cognition among individuals along a spectrum of increased risk for Parkinson's disease. PLoS One. 2018, 13, 8, e0201964. doi:10.1371/journal.pone.0201964.

24. Wyman-Chick, K.A.; Martin, P.K.; Barrett, M.J.; Manning, C.A.; Sperling, S.A. Diagnostic Accuracy and Confidence in the Clinical Detection of Cognitive Impairment in Early-Stage Parkinson Disease. J Geriatr Psychiatry Neurol. 2017, 30, 3, 178-183. doi:10.1177/0891988717701001.

25. Weintraub, D.; Simuni, T.; Caspell-Garcia, C.; Coffey, C.; Lasch, S.; Siderowf, A.; Aarsland. D.; Barone, P.; Burn, D.; Chahine, L.M.; Eberling, J.; Espay, A.J.; Foster, E.D.; Leverenz, J.B.; Litvan I.; Richard, I.; Troyer, M.D.; Hawkins, K.A. Cognitive performance and neuropsychiatric symptoms in early, untreated Parkinson's disease. Mov Disord. 2015, 30, 7, 919-927. doi:10.1002/mds.26170. 
26. McDermott, K. L.; Fisher, N.; Bradford, S.; Camicioli, R. Parkinson's disease mild cognitive impairment classifications and neurobehavioral symptoms. International Psychogeriatrics 2017, 30, 02, 253-260. doi:10.1017/s1041610217002265.

27. Lawrence, B.J.; Gasson, N.; Loftus ,A.M. Prevalence and Subtypes of Mild Cognitive Impairment in Parkinson's Disease. Sci Rep. 2016, 21, 6, 33929. doi:10.1038/srep33929.

28. Gigante, A.F.; Bruno, G.; Iliceto, G.; Guido, M.; Liuzzi, D.; Mancino, P.V.; De Caro M.F.; Livrea, P.; Defazio, G. Action tremor in Parkinson's disease: frequency and relationship to motor and non-motor signs. Eur J Neurol. 2015, 22,2 , 223. doi:10.1111/ene.12583.

29. Galtier, I.; Nieto, A.; Lorenzo, J.N.; Barroso, J. Mild Cognitive Impairment in Parkinson's Disease: Clustering and Switching Analyses in Verbal Fluency Test. J Int Neuropsychol Soc. 2017; 23, 6, 511-520. doi: 10.1017/S1355617717000297.

30. Galtier, I.; Nieto, A.; Lorenzo, J.N.; Barroso J. Mild cognitive impairment in Parkinson's disease: Diagnosis and progression to dementia. J Clin Exp Neuropsychol. 2016, 38, 1, 40-50. doi:10.1080/13803395.2015.1087465.

31. Pfeiffer, H.C.; Løkkegaard, A; Zoetmulder, M.; Friberg, L.; Werdelin, L. Cognitive impairment in early-stage non-demented Parkinson's disease patients. Acta Neurol Scand. 2014, 129, 5, 307-318. doi:10.1111/ane.12189.

32. Cosgrove, J.; Alty, J. E.; Jamieson, S. Cognitive impairment in Parkinson's disease. Postgraduate Medical Journal 2015, 91, 1074, 212-220. doi:10.1136/postgradmedj-2015-133247.

33. Bargiotas, P.; Ntafouli, M.; Lachenmayer, M.L.; Krack ,P.; Schüpbach, W.M.M.; Bassetti , C.L.A. Apathy in Parkinson's disease with REM sleep behavior disorder. J Neurol Sci. 2019, 15, 399, 194-198, doi:10.1016/j.jns.2019.02.028.

34. Zhukova, I.A.; Zhukova, N.G.; Alifirova, V.M.; Nikitina, M.A;. Izhboldina, O.P.. Brazovskaya, N.G. Depression and other non-motor manifestations of Parkinson's disease. Clinical medicine 2017, 95, 4, doi:10.18821/0023-2149-2017-95-5-419-424.

35. Nikitina, A.V.; Fedorova, N.V. Behavioral disorders in Parkinson's disease on the background of dopaminergic therapy. Annals of Clinical and Experimental Neurology 2017, 11, 1, 14-20 (in Russ.).

36. Nodel, M.R.; Obukhova A.V.; Yakhno N.N. he effectiveness of piribedil in neuropsychiatric disorders in the early stages of Parkinson's disease. Neurological journal 2016, 21, 2, 110-116 (in Russ.).

37. Zalyalova, Z.A.; Khasanova, D.M. Depression in patients with early stages of Parkinson's disease. Difficult patient 2016, 14, 4-5, 22-28 (in Russ.).

38. Bogdanov, R.R.; Borisova, S.Yu.; Kotov, S.V. Cognitive and affective disorders in the early stages of Parkinson's disease. Almanac of Clinical Medicine 2015, 39, 90-96 (in Russ.).

39. Akhmadeyeva, G.N.; Magzhanov, R.V. Anxiety-depressive disorders in patients with Parkinson's disease in the Republic of Bashkortostan. Ural medical journal 2015, 125, 2, 44-48 (in Russ.).

40. Fedorova, N.V.; Kulua, T.K..; Gubareva N.N. Depression in Parkinson's disease. The effectiveness of the new antidepressant valdoxan (agomelatine) in the correction of affective and dyssomnic disorders. Psychiatry and psychopharmacotherapy 2015, 17, 4, 9-14 (in Russ.).

41. De Lau, L.M.; Verbaan, D.; Marinus, J.; van Hilten, J.J. Survival in Parkinson's disease. Relation with motor and non-motor features. Parkinsonism Relat Disord. 2014, 20, 6, 613-619. doi:10.1016/j.parkreldis.2014.02.030.

42. Hughes, K.C; Gao, X.; Baker, J.M.; Stephen, C.; Kim ,I.Y.; Valeri, L.; Schwarzschild, M.A.; Ascherio, A. Non-motor features of Parkinson's disease in a nested case-control study of US men. J Neurol Neurosurg Psychiatry 2018, 89, 12, $1288-1295$. doi:10.1136/jnnp-2018-318275.

43. Nodel, M.R. Anxiety in Parkinson's disease. Neurological journal 2018, 23, 4, 176-183 (in Russ.).

44. Hinkle, J.T.; Perepezko, K.; Bakker, C.C.; Dawson, T.M.; Johnson, V.; Mari, Z.; Marvel, C.L.; Mills, K.A.; Pantelyat, A.; Pletnikova, O.; Rosenthal, L.S.; Shepard, M.D.; Stevens, D.A.; Troncoso, J.C.; Wang, J.; Pontone, G.M. Domain-specific cognitive impairment in non-demented Parkinson's disease psychosis. Int J Geriatr Psychiatry 2018, 33, 1, e131-e139. doi:10.1002/gps.4736.

45. Barrett, M.J.; Smolkin, M.E.; Flanigan, J.L; Shah, B.B.; Harrison, M.B.; Sperling, S.A. Characteristics, correlates, and assessment of psychosis in Parkinson disease without dementia. Parkinsonism Relat Disord. 2017, 43, 56-60. doi:10.1016/j.parkreldis.2017.07.011.

46. Weintraub, D.; Simuni, T.; Caspell-Garcia, C.; Coffey C.; Lasch, S.; Siderowf, A., Aarsland, D., Barone, P.; Burn, D.; Chahine, L.M.; Eberling, J.; Espay, A.J.; Foster, E.D.; Leverenz, J.B.; Litvan, I.; Richard, I.; Troyer, M.D.; Hawkins, K.A. Cognitive performance and neuropsychiatric symptoms in early, untreated Parkinson's disease. Mov Disord. 2015, 30, 7, $919-927$. doi:10.1002/mds.26170.

47. Gordon, P.C.; Kauark, R.B.; Costa, C.D.; de Oliveira, M.O.; Godinho F.L; Rocha, M.S. Clinical Implications of the National Institute of Neurological Disorders and Stroke Criteria for Diagnosing Psychosis in Parkinson's Disease. J Neuropsychiatry Clin Neurosci. 2016, 28, 1, 26-31. doi:10.1176/appi.neuropsych.15050119.

48. Rana, A. Q.; Ahmed, U. S.; Chaudry, Z. M.; Vasan, S. Parkinson's disease: a review of non-motor symptoms. Expert Review of Neurotherapeutics 2015, 15, 5, 549-562. doi:10.1586/14737175.2015.1038244.

49. Weintraub, D.; Koester, J.; Potenza, M.N.; Siderowf, A.D.; Stacy, M.; Voon, V.; Whetteckey, J.; Wunderlich, G.R.; Lang, A.E. Impulse control disorders in Parkinson disease: a cross-sectional study of 3090 patients. Archives of Neurology 2010, 67, 5, 589-595. doi:10.1001/archneurol.2010.65.

Garcia-Ruiz, P. J.; Martinez Castrillo, J. C.; Alonso-Canovas, A.; Herranz Barcenas, A.; Vela, L.; Sanchez Alonso, P.; Mahillo Fernandez, I. Impulse control disorder in patients with Parkinson's disease under dopamine agonist therapy: a multicentre study. Journal of Neurology, Neurosurgery \& Psychiatry 2014, 85, 8, 840-844. doi:10.1136/jnnp-2013-306787. 